\title{
PROJETOS COMO JOGOS DE CRIAÇÃO
}

CAVALCANTE, NEUSA

Doutora, Universidade de Brasilia, neusa.cavalcante2@gmail.com

\author{
SILVA, ELIEL AMÉRICO SANTANA DA \\ Doutor, Universidade de Brasília, americoeliel@gmail.com
}

\author{
TRONCOSO, MÁRCIA URBANO \\ Mestre, Universidade de Brasília, marciaurbanotroncoso@gmail.com
}

\section{RESUMO}

Propõe-se aqui uma reflexão sobre os mecanismos pedagógicos capazes de sensibilizar os estudantes de arquitetura, contribuindo tanto para conscientizá-los sobre seu futuro papel social como para desenvolver sua criatividade, requisitos fundamentais para fazer face às adversidades decorrentes de um mundo marcado por rápidas e profundas transformações. Acredita-se que um ensino mais lúdico, onde o projeto se apresente como um jogo de abstração, pode estimular os estudantes a sonharem com alternativas para mundo mais justo e fraterno, enquanto são preparados para responder, de forma adequada, às demandas de uma sociedade que se desenvolve em um cenário de imprevisibilidade. Uma estratégia diferenciada para as disciplinas iniciais do ensino de projeto de arquitetura, baseada em uma metodologia com conteúdos, instrumentos e objetivos bem delineados, pode ser uma aposta eficaz para estimular a autoconfiança e desenvolver a utopia dos estudantes.

PALAVRAS-CHAVE: ensino de projeto; criatividade; abstração; lúdico; utopia.

\section{RESUMEN}

Se propone aquí una reflexión sobre los mecanismos pedagógicos capaces de sensibilizar a los estudiantes de arquitectura, contribuyendo tanto a concienciar a ellos sobre su futuro papel social como para desarrollar su creatividad, requisitos fundamentales para hacer frente a las adversidades derivadas de un mundo marcado por rápidas y profundas transformaciones. Se cree que una enseñanza más lúdica, donde el proyecto se presenta como un juego de abstracción, puede estimular a los estudiantes a soñar con alternativas para un mundo más justo y fraterno, mientras que se están preparando para responder adecuadamente a las demandas de una sociedad que se desarrolla em un escenario de imprevisibilidad. Una estrategia diferenciada para las disciplinas iniciales de la enseñanza del proyecto de arquitectura, baseada en una metodologia com contenidos, instrumentos y objetivos bien delineados, puede ser una apuesta eficaz para estimular la autoconfianza y para el desarrollo de la utopía de los estudiantes.

PALABRAS CLAVES: enseñanza de proyecto; creatividad; abstracción; lúdico; utopía.

\section{ABSTRACT}

It is proposed here a reflection on pedagogical mechanisms that are able to sensitize students of architecture, contributing both to make them aware of their social role and to develop their creativity, fundamental requirements to face adversities arising from a world marked by rapid and deep transformations. It is believed that a more playful teaching, where project presents itself as a game of abstraction, can stimulate students to dream of alternatives for a more just and fraternal world, while they are being prepared to respond adequately to social demands in a scenario of unpredictability. A differentiated strategy for the initial disciplines of project teaching, based on a methodology with well-delineated content, tools and objectives, can be an effective bet to stimulate students' self-confidence and to develop their utopias. KEYWORDS: project teaching; creativity; abstraction; ludic; utopia.

\section{INTRODUÇÃO}

Um mundo marcado por incertezas políticas, rápidas transformações, destruição progressiva de postos de trabalho e descartabilidade de soluções e produtos, obriga a uma constante atualização de saberes e práticas, colocando em pauta a necessidade de uma reflexão sobre metodologias de ensino capazes de conduzir a novas respostas para demandas de uma sociedade que se desenvolve em um cenário de imprevisibilidade.

No atual momento histórico, ou na 'modernidade líquida', conforme definiu Zygmunt Bauman em $O$ mal-estar da modernidade (1997), o tempo se sobrepõe ao espaço, fazendo com que nos movimentemos sem sair do lugar, e vivamos rodeados de sinais confusos, propensos a mudar com rapidez e de forma imprevisível. Com o avanço das comunicações e o advento da sociedade em rede, é disponibilizada, por meio de diversas mídias 
e aplicativos, uma enorme quantidade de informações, sem que haja tempo suficiente para sua assimilação e interpretação.

No caso do ensino de arquitetura, cabe um esforço no sentido de ampliar as oportunidades de os estudantes experimentarem e inventarem mais, ao invés de serem afogados em um mar de informações, transmitidas, muitas vezes, de forma isolada e desconexa, sem que possam ser claramente percebidos seu verdadeiro significado teórico e sua importância profissional. Trata-se, portanto, de desenvolver estratégias capazes de estimular a criatividade: mais do que treinados para serem personagens de cenários já desenhados, os estudantes devem ser preparados para antecipá-los, recriá-los; mais do que aprender a seguir dogmas, eles devem estar libertos para sonhar e criar. Como afirmou Paulo Freire, [...] ensinar não é transferir conhecimento, mas criar as possibilidades para sua produção ou sua construção (1997, p. 52).

A despeito das possibilidades abertas pelo surgimento de novas técnicas, novos materiais de construção e recursos computacionais, o projeto de arquitetura segue sendo uma atividade complexa. Fazer com que um jovem, vindo geralmente de escolas onde as disciplinas são oferecidas de forma estanque, seja capaz de agrupar diferentes saberes para a produção de artefatos arquitetônicos - ou formas esperando virar arquitetura - criativos e inovadores, parece uma missão quase impossível.

Com base na longa experiência à frente das disciplinas de Geometria Construtiva ( $1^{\circ}$ semestre) e Projeto de Arquitetura, Linguagem e Expressão ( $2^{\circ}$ semestre), do Curso de Arquitetura e Urbanismo da Universidade de Brasília, defende-se a presença de atividades voltadas à sensibilização em relação às características das formas bi e tridimensionais e ao valor expressivo dos elementos geométricos - ponto, linha, plano e volume. Para tanto, além de exercícios de abstração, considera-se importante a realização de experimentações intuitivas em torno das possibilidades estruturais. Fazendo um recorte pedagógico, propõe-se que os primeiros semestres de projeto sejam dedicados prioritariamente às questões intrínsecas à forma, à percepção tátil-visual, em detrimento daquelas de caráter mais pragmático. Livres das demais condicionantes do projeto - funcionais, ambientais, ergonômicas, etc. -, os estudantes podem se dedicar, de forma mais plena, à criação e construção, por meio da geometria e de diretrizes compositivas, de objetos visualmente instigantes e belos. Para Tadao Ando, a importância da arquitetura é encontrada na distância entre ela e a função (apud PALLASMAA, 2011, p. 59).

Para os períodos iniciais, defende-se a adoção de uma metodologia baseada em três pilares principais: o lúdico, a abstração e a utopia. O lúdico, como forma subliminar de desenvolvimento intelectual e artístico, está na gênese do pensamento, da descoberta de si mesmo, da possibilidade de experimentar e criar. A abstração, cuja raiz está na construção de novas formas de apropriação do real, contribui para multiplicar as possibilidades de criação. Por sua vez, ampliando o conhecimento sobre o universo, a utopia, ou o não-lugar, enseja a possibilidade de transformá-lo. Lúdico, abstração e utopia implicam rompimento de limites: o lúdico, como fator de extrapolação ou subversão da realidade cotidiana; a abstração, como possibilidade de ampliação da capacidade tátil-visual e intelectual; e a utopia, como ruptura entre razão e imaginação. $O$ ato criativo pressupõe a existência de um espírito lúdico, que se apropria da abstração como ferramenta para a construção da utopia, em continuadas ações de experimentação.

O processo pedagógico transforma-se assim em um jogo que, no caso da Geometria Construtiva, tem como ponto de partida a natureza, como ferramenta a abstração e como resultado um objeto criativo que, por sua capacidade de antecipação, pode resultar em uma utopia. A principal regra é a criatividade, entendida, por um lado, como postura crítico-reflexiva diante da realidade e, por outro, como capacidade, ou presunção, de contribuir para transformá-la. O jogo se desenvolve em um campo experimental, onde é permitido avançar e recuar, fazer e refazer, construir e desconstruir, antes do encerramento da 'partida'. Assimilada a metodologia desse exercício considerado fundador, podem ser eleitos, em diferentes universos culturais - pintura, poesia, dança, cidad, etc. - outros referenciais para novos jogos, no mesmo espaço experimental.

No Projeto Arquitetônico, Linguagem e Expressão, em um primeiro momento, trata-se de desenvolver o vocabulário da forma: estudos para uma praça, por exemplo, têm como objetivo a compreensão das características expressivas do ponto, da linha e dos planos horizontais e verticais.

Em seguida, para compreender a sintaxe morfológica, os alunos devem se debruçar sobre a análise de projetos arquitetônicos significativos, visando a percepção das relações que se estabelecem entre as formas e os espaços nas quais estão inseridas. Tendo como base as organizações espaciais - central, linear, radial, em malha, aglomerado, observáveis nos projetos analisados, são desenvolvidos, por meio de desenhos e maquetes convencionais, propostas de espaços utópicos a serem implantados em sítios, existentes ou não, de livre escolha dos alunos. Com domínio do vocabulário e da gramática formal, os alunos adquirem maturidade para, a partir de referências concretas - tais como ponte, muro, mirante, cais, etc. -, criar projetos conceituais, ou poesias da forma. Cada resultado parcial é, ao mesmo tempo, um experimento e um produto 
(figura 1), configurando uma estratégia que tem, no processo, a possibilidade do erro e, no produto, a probabilidade do acerto.

Figura 1: Projetando utopias: o experimento e o produto.
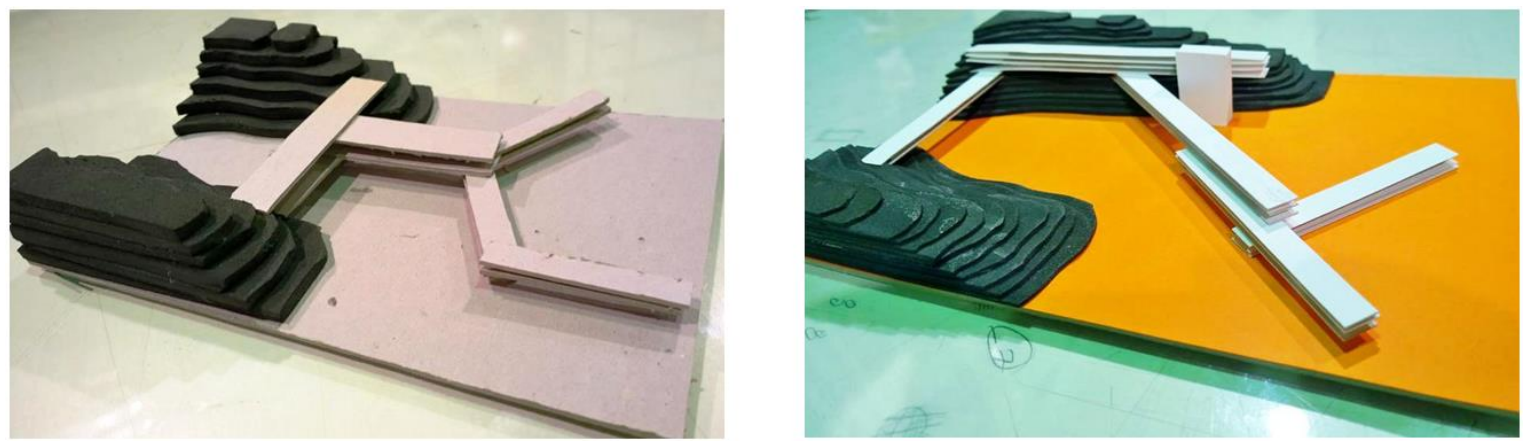

Fonte: Acervo dos autores.

Para concluir, pode-se acrescentar que, além das metodologias desenvolvidas para atingir objetivos particulares e específicos, é também papel da educação, principalmente nos níveis iniciais do curso, conscientizar os estudantes sobre o compromisso político e social do artista/arquiteto, que, embora não se dê de forma imediata e por ações diretas, ocorre por meio da repercussão de sua interpretação da realidade. Segundo Tiago Nunes, é pela via indireta que o trabalho do artista se realiza. É pelo recurso ao indireto, pelo apelo à significação possível, que ele é capaz de ampliar os sentidos de sua mensagem e propor respostas que ressoem pelas sociedades (2009, p. 149).

\section{TRIPÉ METODOLÓGICO}

\section{A abstração}

Desenvolvimento do artigo, envolvendo um ou mais subtítulos numerados. Desenvolvimento do artigo, envolvendo um ou mais subtítulos numerados. Desenvolvimento do artigo, envolvendo um ou mais subtítulos numerados. Desenvolvimento do artigo, envolvendo um ou mais subtítulos numerados.

Desenvolvimento do artigo, envolvendo um ou mais subtítulos numerados. Desenvolvimento do artigo, envolvendo um ou mais subtítulos numerados. Desenvolvimento do artigo, envolvendo um ou mais subtítulos numerados. Desenvolvimento do artigo, envolvendo um ou mais subtítulos numerados.

A abstração consiste em uma operação mediante a qual alguma coisa é escolhida como objeto de percepção, atenção, observação, consideração ou estudo, sendo, para tanto, isolada de outras coisas com que mantém relação. Sendo assim, a abstração decorre de duas intenções: isolar a coisa previamente escolhida daquelas com as quais mantém relação e assumir como objeto específico de consideração aquilo que foi isolado. De acordo com Carlos Arís (2000), a abstração constitui um procedimento cognitivo que tende a separar os aspectos acidentais ou contingentes dos essenciais ou necessários, permitindo extrair um conceito universal a partir de diversas situações ou objetos particulares. Assim, qualquer operação analítica, que comporte a substituição das partes de um todo por entes geométricos ou a decomposição de um todo em seus elementos básicos, implica um grau de abstração.

Para Wilhelm Worringer (1908, apud JUNG, 2012), a motivação em relação à abstração surgiu, para o homem da pré-história, como um fator de repouso diante das arbitrariedades dos fenômenos naturais e devido às falhas da percepção humana na apreensão da realidade. Segundo ele, a tradução desses fenômenos nas formas claras e objetivas da geometria, com suas estruturas estáveis como as que regem as leis morfológicas dos cristais, seria capaz de produzir um efeito tranquilizador.

Atormentados pela confusão e jogo mutável dos fenômenos do mundo exterior, os povos ditos primitivos eram dominados por uma necessidade absoluta de repouso. A felicidade que procuravam na arte não consistia tanto em mergulharem nas coisas do mundo exterior ou nele se deleitarem, mas em retirar o objeto individual de sua contingência arbitrária e aparente e torná-lo eterno pela aproximação às formas abstratas e, assim, encontrar um lugar de repouso na fuga dos fenômenos [...] as formas abstratas são, pois, as únicas e as melhores onde o homem pode descansar em face da terrível confusão dada pela imagem do mundo real (WORRINGER apud JUNG, 2012, p. 307).

Mas a arte abstrata propriamente dita, definida como manifestação do final do século XIX e início do século $\mathrm{XX}$, resultou de um movimento que, tendo explodido quase concomitantemente em várias partes da Europa, 
se revestiu de um caráter consciente e deliberado de busca, alimentado pela utopia de um mundo novo. Ao mesmo tempo em que se valorizava a máquina e a dinâmica produtiva dela decorrentes, apostava-se no surgimento de um novo homem, capaz de administrá-la, contribuindo para uma sociedade mais justa. Assim, só se pode falar de abstração com propriedade, sobre as obras decorrentes da cultura da modernidade, que consagra a plena coesão interna da forma como o único critério de legitimidade para a obra de arte (ARís, 2000, p. 8).

Ainda segundo Worringer, como nem sempre era possível a comunhão com um mundo exterior em constantes transformações, devido aos sentimentos de ansiedade e angústia (anxiety) que gerava, a busca dos artistas das vanguardas modernas recaiu, em geral, sobre as formas de expressão distanciadas dessa realidade. Como os povos pré-históricos, eles se voltaram à abstração (figura 2), como forma de crítica e de resistência aos impactos das adversidades.

Figura 2: A vaca, 1917, Theo van Doesbug.

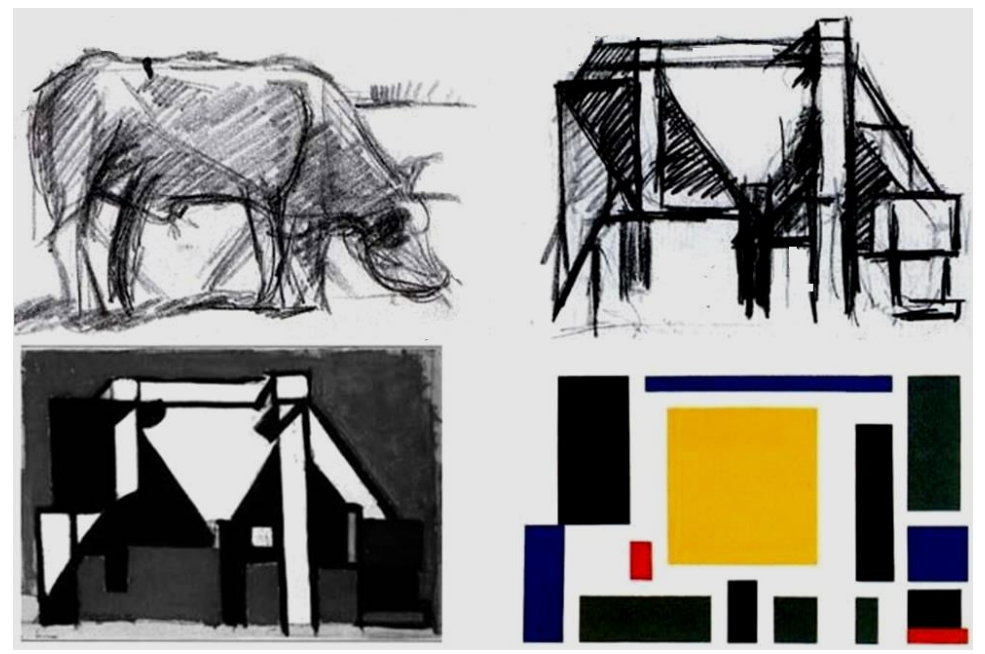

Fonte: Acervo do Museu de Arte Moderna (MOMA), Nova lorque. ${ }^{1}$

Refletindo sobre os dias atuais, Bauman (2017), em seu livro Estranhos à nossa porta, afirma que as dificuldades para enfrentar situações que não produzimos nem controlamos é uma importante causa de ansiedade e medo, que enseja, em contrapartida, reações e diferentes formas de resistência, sendo que muitas das quais podem ser buscadas na arte, cujo papel crítico encontra na modernidade sua maior expressão.

Ao longo do tempo, a arte tem estado estreitamente vinculada à natureza, seja como imitação, criação ou construção. Enquanto Platão defende que a arte é totalmente dependente da natureza, para Schelling ela é uma continuação da atividade divina. Hegel a vê como uma forma de resolução de problemas estéticos com vistas a uma nova situação espiritual, e Kant, por sua vez, admite que a arte, embora não prescindindo da natureza, subordina-a a si, fazendo com que o artista se torne um importante protagonista dessa transformação.

Como as artes plásticas, a arquitetura é também subsidiária da natureza, uma fonte inesgotável de elementos e padrões geométricos, que podem ser observados, apropriados e transformados durante o processo de projeto. Ao longo do tempo, a relação entre natureza e arquitetura tem assumido diferentes vieses. Acatando a visão platônica, da arte como imitação, a natureza tem servido de motivo para múltiplos ornamentos, que variam das folhas de acanto aos caracóis. Seguindo o conceito hegeliano de arte como criação, enquadramse os exemplos da arquitetura mimética. E, contemplando as premissas de Kant, que vê a arte como construção, pode-se dizer que, a partir de análises e intensivos processos de abstração, foram realizadas muitas obras de arquitetura inspiradas na morfologia e nos padrões geométricos encontrados nos seres orgânicos.

A arquitetura de Gaudí - para quem O grande livro sempre aberto e que se deve tratar de ler é o da natureza -, expressa modos diferenciados de relação com a natureza. De um lado, o arquiteto catalão projetou diversos elementos decorativos, com base na observação direta; e, de outro, concebeu uma arquitetura original e surpreendente (figura 3), por meio do que chamou de "teoria da geometria regrada", fruto de um acurado processo de abstração (apud PUIG, 2011, p. 25). 
Figura 3: Gaudí: Cripta Güel (1898), Colégio Teresiano (1888), Casa Milà (1905), Barcelona.
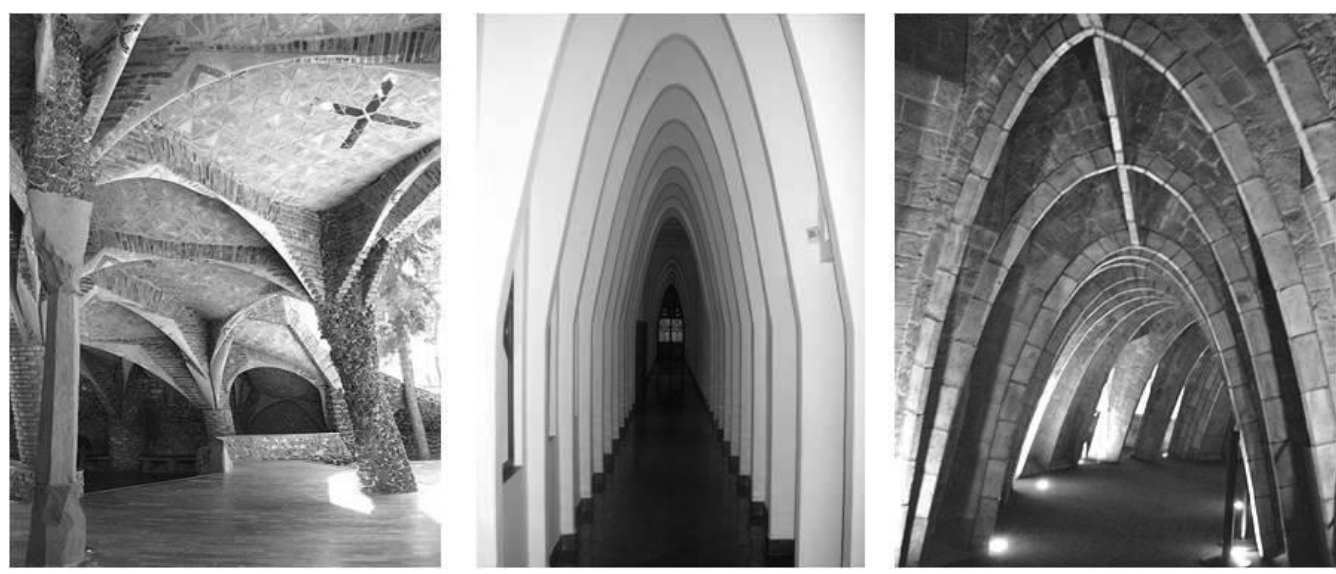

Fonte: Wikimedia Commons e blog Descobrint BARCELONA².

No século $\mathrm{XX}$, a necessidade de "desenhar para as máquinas", com vista à produção em massa, implicou uma busca pela essência, com ênfase na ortogonalidade, na expressão clara de uma geometria euclidiana, capaz de se traduzir em um racionalismo de caráter universal. Le Corbusier, em seu livro Por uma arquitetura (1923), chama a atenção para a necessidade de produzir construções verdadeiramente modernas e adaptadas ao espírito de uma nova era, assim como os carros, os aviões e os transatlânticos. As máquinas, com suas formas puras e sua eficiência técnica, eram então as referências estéticas para a arquitetura moderna.

[...] enquanto o objetivo principal da investigação científica é formular princípios abstratos e leis universais a partir da observação dos fenômenos, a principal finalidade do fazer artístico é, pelo contrário, a elaboração de objetos físicos, que surgem como destilação das ideias e conceitos com os quais tratamos de interpretar a realidade (ARÍS, 2003, p. 44).

Com os progressivos avanços da tecnologia, criaram-se novas possibilidades de construir edifícios, formalmente mais complexos, inspirados em morfologias orgânicas, como, por exemplo, algumas obras de Santiago Calatrava (figura 4).

Figura 4: Calatrava: Cidade das Artes e da Ciência, Valência (1996), e Gare Oriente (1994), Lisboa.

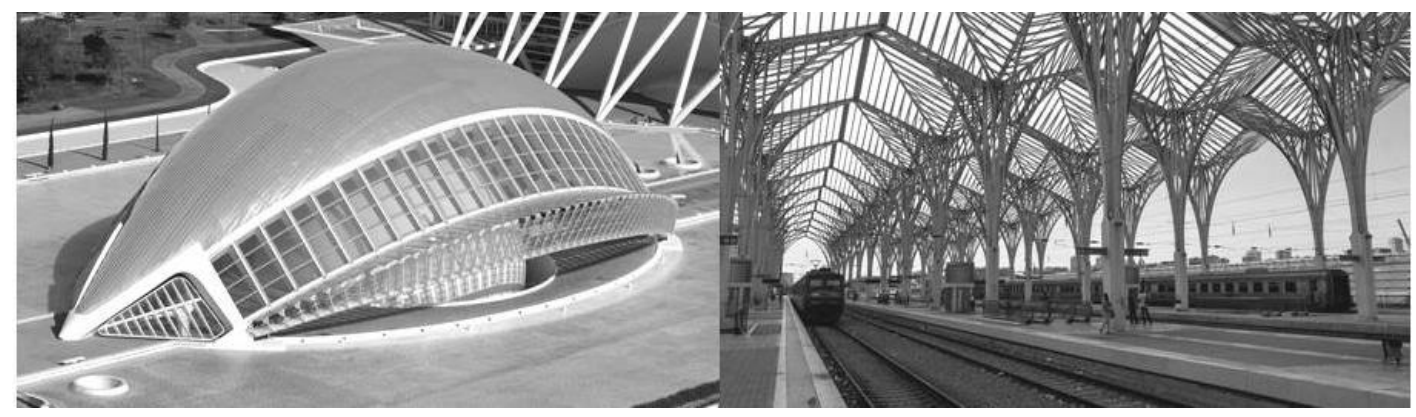

Fonte: Wikipedia e Wikimedia Commons ${ }^{3}$.

A natureza tem sido uma importante fonte de conhecimento também para os profissionais preocupados com a funcionalidade e a qualidade ambiental dos espaços. A arquitetura biomimética, que estuda tanto a forma como o funcionamento da natureza, vem sendo, cada vez mais, objeto de pesquisas multidisciplinares, que objetivam soluções mais sustentáveis. Além disso, os recentes avanços na tecnologia da informação têm permitido realizar sofisticadas abstrações com vistas à construção de estruturas paramétricas.

No entanto, não basta ter acesso aos diferentes aparatos tecnológicos, já que, a partir de parâmetros previamente definidos no software, tem-se uma série de opções formais para atender a um mesmo objetivo. Com isso, mais do que suportes para expressar e representar ideias, as recentes tecnologias da computação passam a interferir no próprio processo da concepção arquitetônica. No entanto, para extrair o que há de melhor na relação homem-máquina é necessário mais do que experiência e disposição para explorar as potencialidades dos recursos tecnológicos. Além da escolha correta dos softwares e do domínio de seus procedimentos técnicos, impõe-se a necessidade de muita experimentação e criatividade, como forma de compensar o distanciamento entre o criador e o objeto, a que se refere Pallasmaa (2011), em seu livro Os olhos da pele: 
[...] a criação de imagens por computador tende a reduzir nossa magnífica capacidade de imaginação multissensorial, simultânea e sincrônica [...] O computador cria uma distância entre o criador e o objeto, enquanto o desenho à mão e a elaboração de maquetes convencionais põem o projetista em contato tátil com o objeto ou o espaço (PALLASMAA, 2011, p. 12).

Tentar minimizar o distanciamento entre o arquiteto e seu produto é um objetivo comum das disciplinas de Geometria Construtiva e Projeto de Arquitetura - Linguagem e Expressão. Acredita-se que o fazer e refazer desenhos e maquetes contribui sobremaneira para estimular o processo criativo dos alunos. Uma sucessão de exercícios, sobre temas previamente escolhidos, contribui para manter o espírito de busca, desenvolver a acuidade tátil-visual e ampliar o repertório plástico-formal.

No âmbito de Geometria Construtiva, os exercícios iniciais de abstração são voltados para os objetos da natureza, mais especificamente para as geometrias presentes, de modo explícito ou implícito, nas formas orgânicas. Ampliação, rotação, espelhamento, simplificação são alguns dos recursos usados para viabilizar a composição plástica, decorrente desse processo de abstração (figura 5).

Figura 5: Era uma vez um abacaxi.

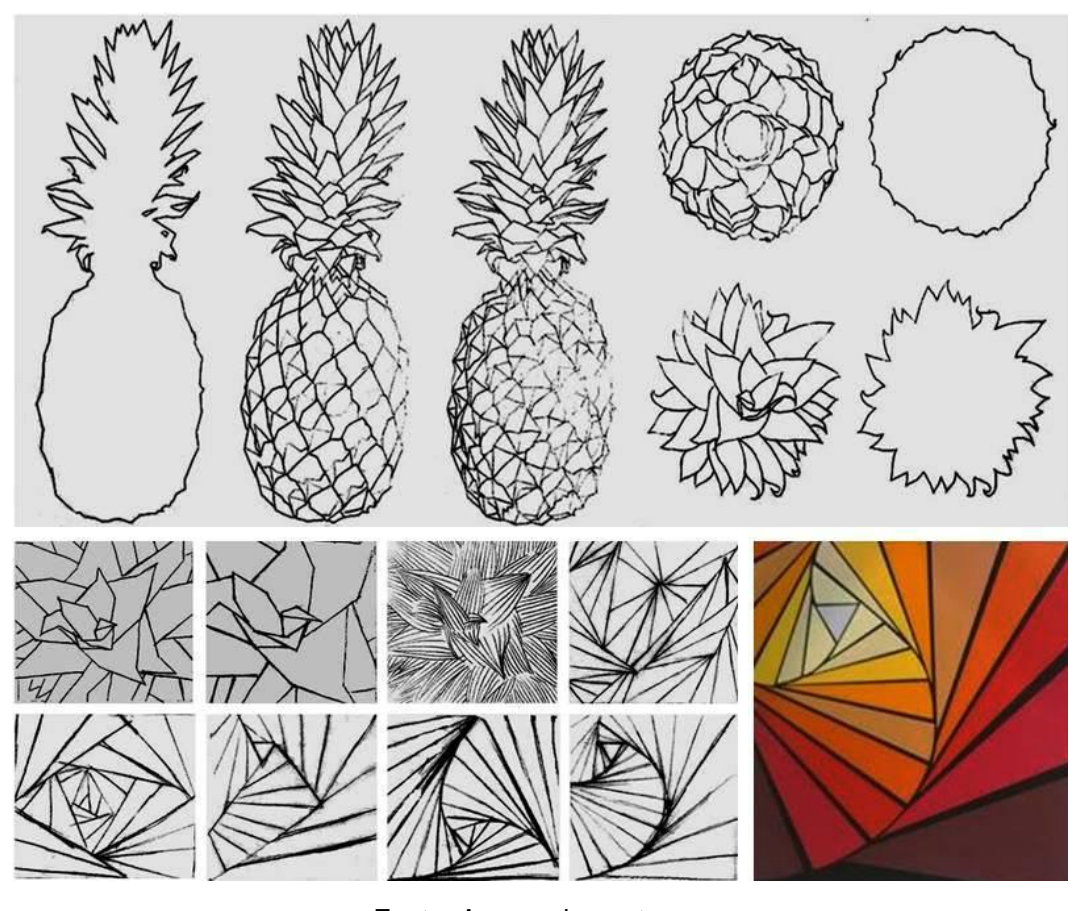

Fonte: Acervo dos autores.

São estudados também os corpos (cheios) e suas relações com os espaços (vazios). Nesse caso, a dança ou o circo podem ser pretextos interessantes para os exercícios de abstração (figuras 6, 7 e 8).

Figura 6: No ritmo de Michael Jackson.

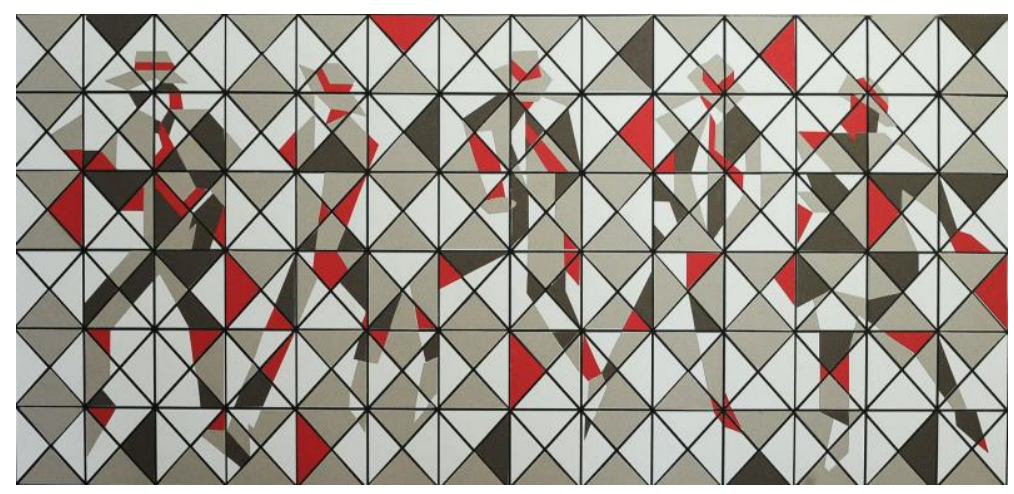

Fonte: Acervo dos autores. 
Figura 7: Corpos em (des)equilíbrio.

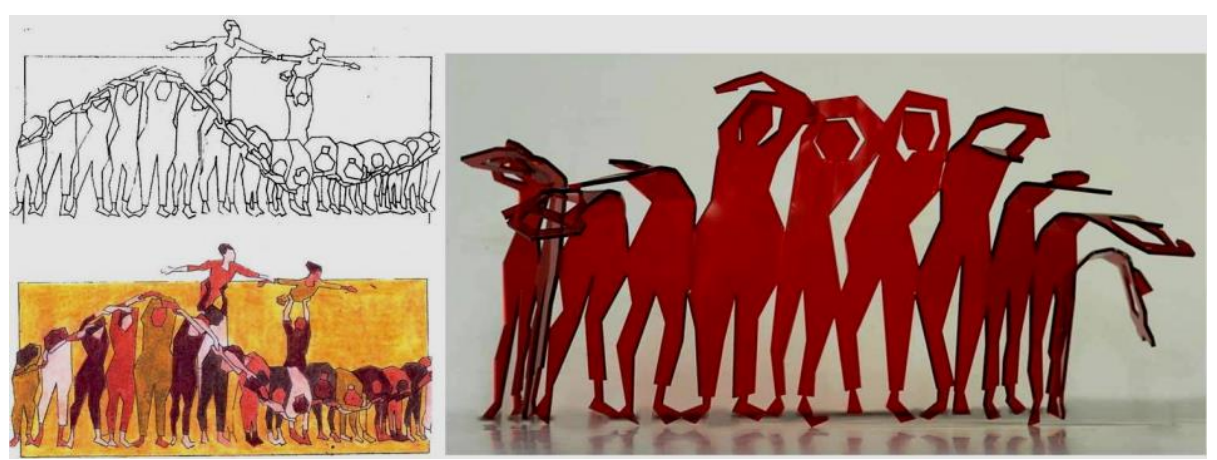

Fonte: Acervo dos autores.

Figura 8: Explorando os movimentos do corpo na dança indiana Sattriya.
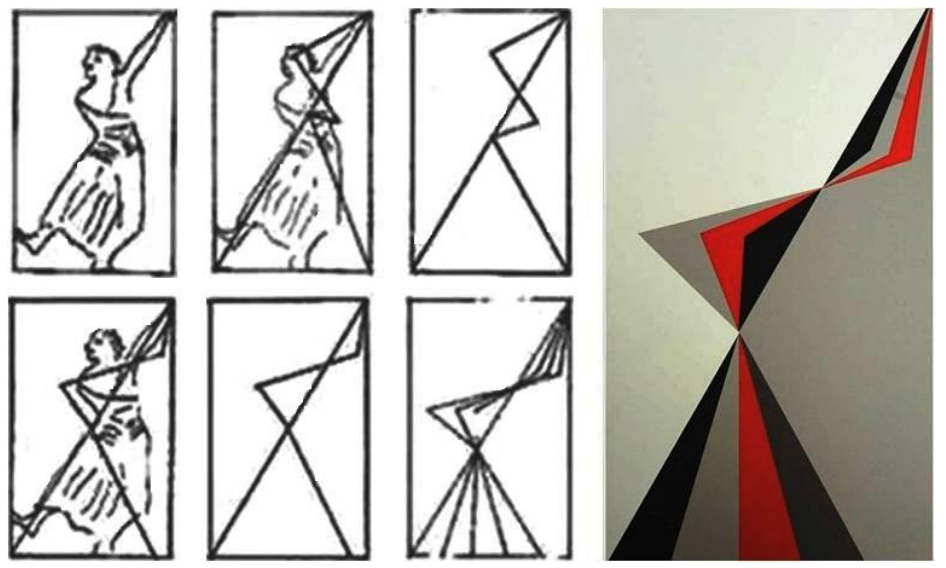

Fonte: Acervo dos autores.

No Projeto de Arquitetura, os exercícios de abstração têm início pela análise de projetos existentes e seus respectivos entornos. Por meio da realização de maquetes, os alunos percebem como o contexto urbano e 0 sítio físico podem sugerir regras ao jogo projetual, ou como importantes arquitetos decidem, durante o processo criativo, quais organizações espaciais devem tomar como base para o lançamento de seus partidos arquitetônicos. No caso da disciplina, são escolhidos e sorteados projetos cujas estruturas formais se enquadram em cinco grandes categorias espaciais, a saber: central, linear, radial, em malha ou aglomerado (figura 9).
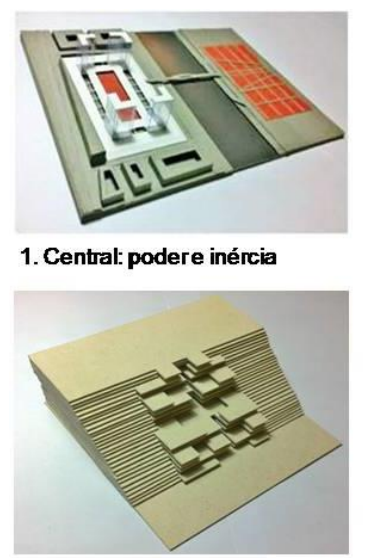

4. Malha-módulose adaptaçāo à topografia

Figura 9: Relendo projetos reais.

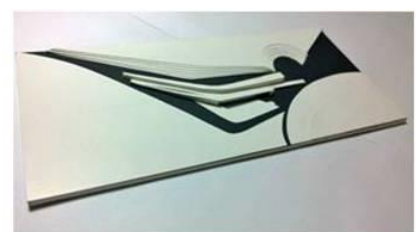

2. Linear. movimento e direçāo

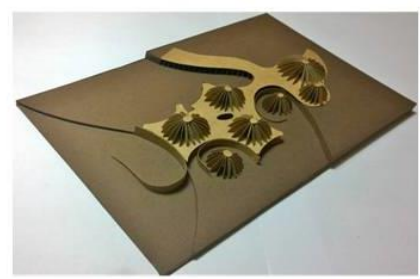

5. Aglomerado-diversidade e proximidade

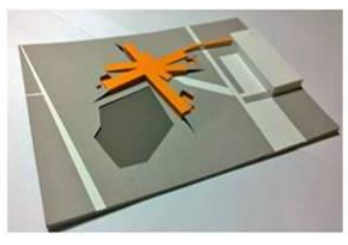

3. Radial: explosāo de tentáculos

1. Bblioteca da França,

Dominique Perrault, 1997

2. Pavilhāo da Paisagem,

Zaha Hadid, Alemanha, 1996

3. Hospital Psiquiátrico

Ellsinore, BIG, Dinamarca,

2010

4. Casa Rokko, Tadao Ando

Osaka, 1983

5. Escola de Dança de Cuba,

Vittorio Gatti, 1963.

Fonte: Acervo dos autores.

Após a compreensão das diferentes características de cada uma dessas organizações, os alunos passam a entender melhor as regras compositivas, ficando mais motivados e mais aptos para fazer abstrações em torno dos projetos estudados (figura 10). Explica-se que criar é um processo de síntese que se diferencia da análise 
realizada anteriormente, em que, partindo de um projeto pré-existente, produziram uma maquete esquemática e fizeram vários croquis até desvendar as ideias e regras utilizadas pelo arquiteto. As imagens abaixo mostram o resultado do processo criativo dos alunos submetidos à regra principal, ou seja, respeitar e deixar evidente a estrutura formal da organização espacial a eles designada por sorteio.

Figura 10: Reinterpretando as organizações espaciais estudadas.

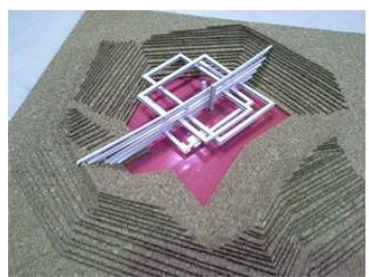

1. A centralidade dentro do vulcāo

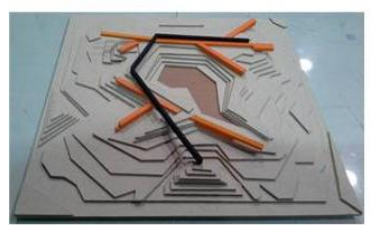

3. A radialidade explode o muro Trump

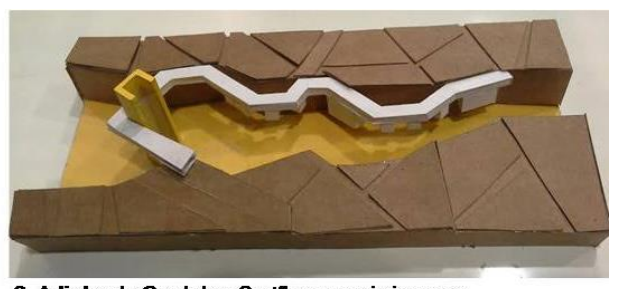

2. A linha do Cordel no Sertâo que vai virar mar

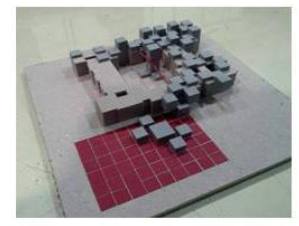

4. A malha do proletariado invade o palácio

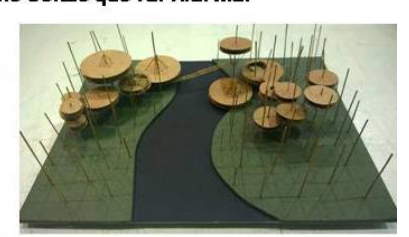

5. O aglomerado na Floresta

Fonte: Acervo dos autores.

\section{O lúdico}

Para fazer frente a um mundo do consumo e do descartável, que coloca à disposição uma enorme gama de dispositivos e aplicativos de toda sorte, é fundamental tornar as atividades acadêmicas em geral, e as de projeto de arquitetura em particular, mais atraentes para os jovens, constantemente assediados e fascinados pelas diferentes mídias. Talvez o lúdico, por sua intensidade, fascinação e capacidade de excitar, constitua uma estratégia capaz de seduzir os estudantes, conscientizando-os sobre a importância e a beleza do saber e do fazer (HUIZINGA, 2000, p.6).

Depois de lamentar o fato de as ciências sociais darem pouca atenção ao papel do lúdico para a civilização, Johan Huizinga afirma que "[...] o jogo se baseia na manipulação de certas imagens, numa certa 'imaginação' da realidade, (ou seja na transformação desta em imagens)". E que o jogo contribui para a percepção do tempo, "[...] enquanto está decorrendo, tudo é movimento, mudança, alternância, sucessão, alteração, separação"; do espaço "[...] todo jogo se processa no interior de um campo delimitado, de maneira material, ou imaginária, deliberada ou espontânea"; e da ordem "[...] o jogo cria ordem e é ordem, introduzindo na confusão da vida e na imperfeição do mundo, uma perfeição temporária e limitada", que proporciona momentos de tranquilidade e segurança (2000, p. 7 e 8 ). E o autor conclui:

É talvez devido à afinidade entre a ordem e o jogo que este parece estar em tão larga medida ligado ao domínio da estética. [...] Em suas formas mais complexas, o jogo está saturado de ritmo e de harmonia, que são os mais nobres dons de percepção estética de que o homem dispõe. São muitos e bem íntimos os laços que unem o jogo e a beleza (HUIZINGA, 2000, p. 11 e 14).

A ordem, fundamental para os profissionais responsáveis pela organização plástico-funcional do espaço, constitui também um importante fator pedagógico, contribuindo para que, durante o processo de ensinoaprendizagem, o respeito às diretrizes metodológicas funcione como garantia do cumprimento dos objetivos previamente definidos.

Finalmente o lúdico está associado diretamente ao ato criativo, como observa Domenico De Masi: a principal característica da atividade criativa é que ela praticamente não se destaca do jogo e do aprendizado, ficando difícil separar essas três dimensões que antes, em nossa vida, tinham sido separadas de maneira clara e artificial (2000, p. 10).

É parte na disciplina Projeto de Arquitetura - Linguagem e Expressão a proposição de diretrizes para o exercício de criação. Como em todo jogo, antes de seu início, são explicitadas as regras e os procedimentos para atingir os objetivos desejados. Com um maior domínio do vocabulário e da gramática da sintaxe formal adquirido a partir dos exercícios iniciais, os alunos tornam-se aptos a criar suas próprias poesias espaciais, tendo sempre em mente, no entanto, a regra básica: liberdade para criar, desde que se mantenha evidente o conceito - mirante, cais, muro e ponte -, expresso nas 'cartas' sorteadas para o jogo. É curioso observar como cada um desses conceitos pode gerar, a partir de terrenos de livre escolha, interpretações muito distintas por alunos de uma mesma turma, o que indica que cada um consegue desenvolver uma linguagem 
e uma expressão próprias (figuras 11). Essas interpretações prendem-se aos múltiplos significados que cada um desses conceitos pode admitir: mirante pode estar associado à amplitude visual, mas também à escalada, alvo, contemplação, etc.; cais pode indicar transição entre terra e água ou entre sólido e líquido, ou flutuação, leveza, segurança, etc.; muro refere-se à defesa, barreira, solidez, fortaleza, mas pode expressar também o escondido, o mistério, etc.; e ponte, além de conexão e união, pode ser passagem, caminho, dentre outras interpretações possíveis.

Figura 11: Exemplos de exercícios a partir dos conceitos: mirante, cais, muro e ponte.
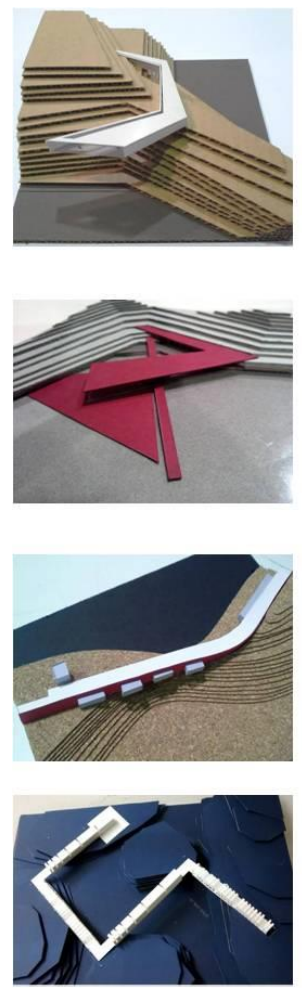

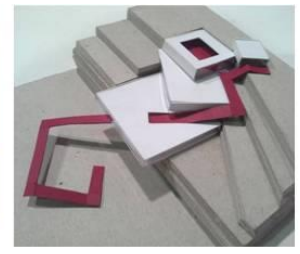

Mirantes

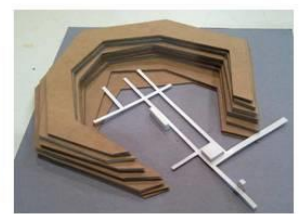

Cais

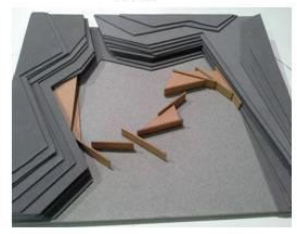

Muros

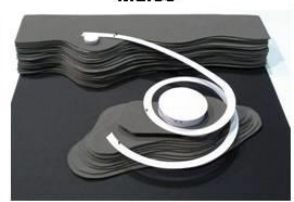

Pontes
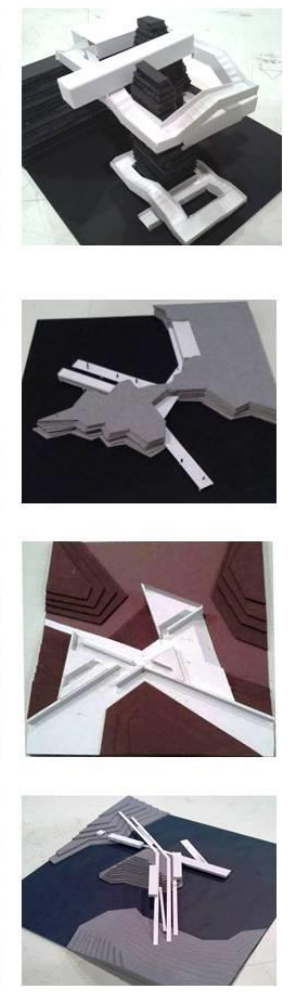

Fonte: Acervo dos autores.

\section{A utopia}

No passado, grandes arquitetos, deixando-se sensibilizar por ideais humanistas, contaminaram suas obras com o desejo de um novo mundo. Muitos foram os que entraram para a história da arquitetura mesmo sem terem realizado muitas obras, como é o caso de Antonio Sant'Elia, que, em 1912, com a sua ousada e visionária Città Nuova. Suas ideias impressionaram os Construtivistas Soviéticos e também os adeptos dos movimentos Situacionista, Metabolista, Archigram e Superstudio, cujas contribuições relativas às possibilidades de novas interpretações e antecipações da realidade foram significativas.

Mesmo reconhecendo que a arte não pode substituir a prática política, Herbert Marcuse admite que, ao insistirem no valor da verdade do sonho, os artistas defendem que as imagens da liberdade e satisfação ainda não alcançadas estariam presentes como ideias reguladoras da razão, do pensamento e das práticas pela construção e reconstrução de valores sociais. Para o autor, enquanto a realização progressiva do sonho e sua preservação são tarefas da luta por uma sociedade melhor, sustentar o sonho contra uma sociedade que não sonha é a grande função subversiva da arte, por ele chamada de 'promessa de felicidade'. Segundo Marcuse, [...] o artista dissocia-se metodicamente da sociedade alienada e cria o irreal, universo 'ilusório' no qual a arte por si só tem e comunica sua verdade (1972, p.97). Reforçando essa reflexão, Bosi lembra que

[...] alguns traços formadores da cultura moderna conferem à ciência e às artes um caráter de resistência, ou a possibilidade de resistência, às pressões estruturais dominantes em cada contexto [...] Esse vetor da cultura como consciência de um presente minado por desequilíbrios é o momento que preside à criação de alternativas para um futuro de algum modo novo. (2002, p. 17).

Embora tenha como atribuição profissional projetar edifícios para diferentes demandas da sociedade, os arquitetos não devem perder a perspectiva de participar da transformação da realidade na qual estão inseridos. Essa vocação transformadora, que está no cerne da própria atuação do artista/arquiteto, nem sempre surge de forma espontânea, decorre, em geral, de um trabalho de conscientização e motivação, que 
deve acontecer no espaço de ensino, como objetivo do processo pedagógico. É sonhando com um mundo mais justo e fraterno que os artistas e os arquitetos podem construir talvez o seu mais importante legado. Mas, desenhar utopias é uma tarefa difícil, como observa Federico Fellini: [...] exprimir um sonho, uma fantasia, é uma operação de alta matemática, como lançar uma nave no espaço. A expressão exige um máximo de rigor (1995, p. 97).

Assim é que, na Geometria Construtiva, cidades reais ou fictícias tornam-se temas privilegiados para especulações em torno da construção de utopias bi e tridimensionais (figuras 12 e 13).

Figura 12: Reinventando uma favela carioca.

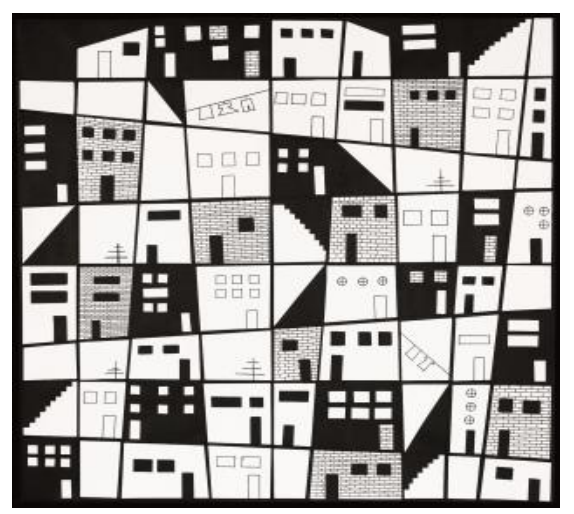

Fonte: Acervo dos autores.

Figura 13: Trazendo à luz As Cidades Invisíveis (1972) de Italo Calvino.

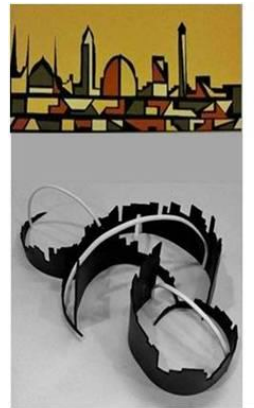

Filide
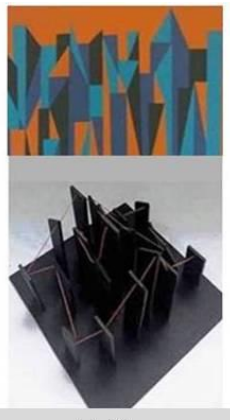

Ercilia
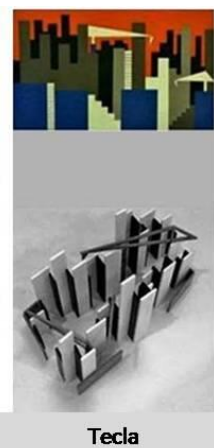

Tecla

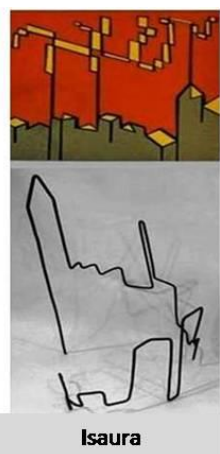

Isaura

Fonte: Acervo dos autores.

Na disciplina de Projeto de Arquitetura - Linguagem e Expressão, a motivação para a utopia pode vir, por exemplo, de obras de importantes artistas (figuras 14, 15 e 16).

Figura 14: No passo da Caravana (1948) de Salvador Dalí.

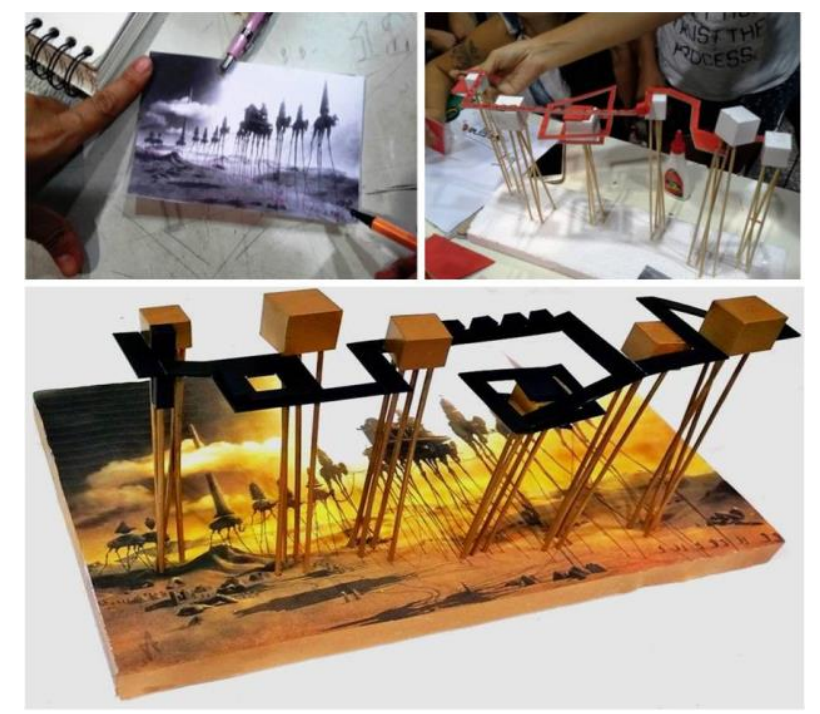

Fonte: Acervo dos autores. 
Figura 15: Sonhando na Noite Estrelada (1889) de Vincent Van Gogh.
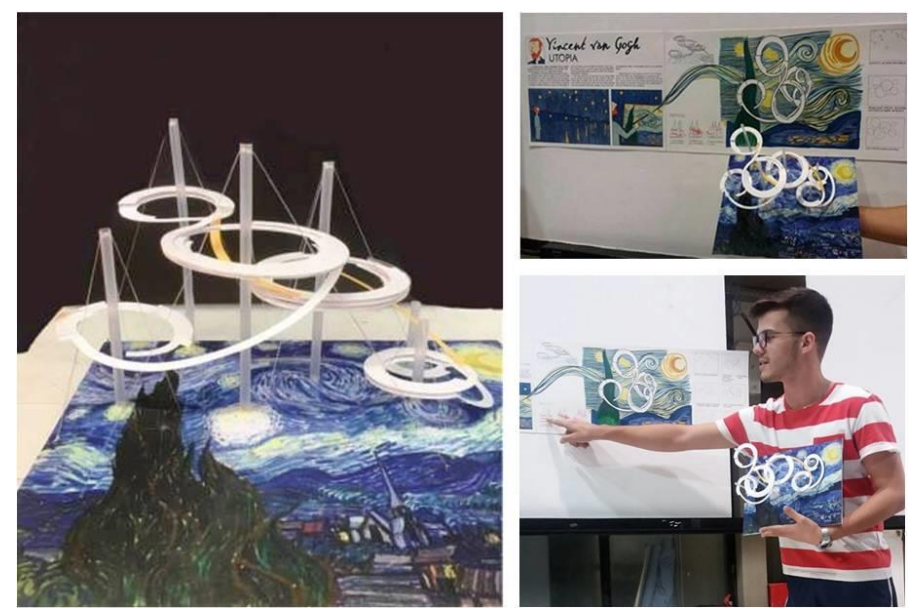

Fonte: Acervo dos autores.

Figura 16: Revisitando a obra de Piet Mondrian.

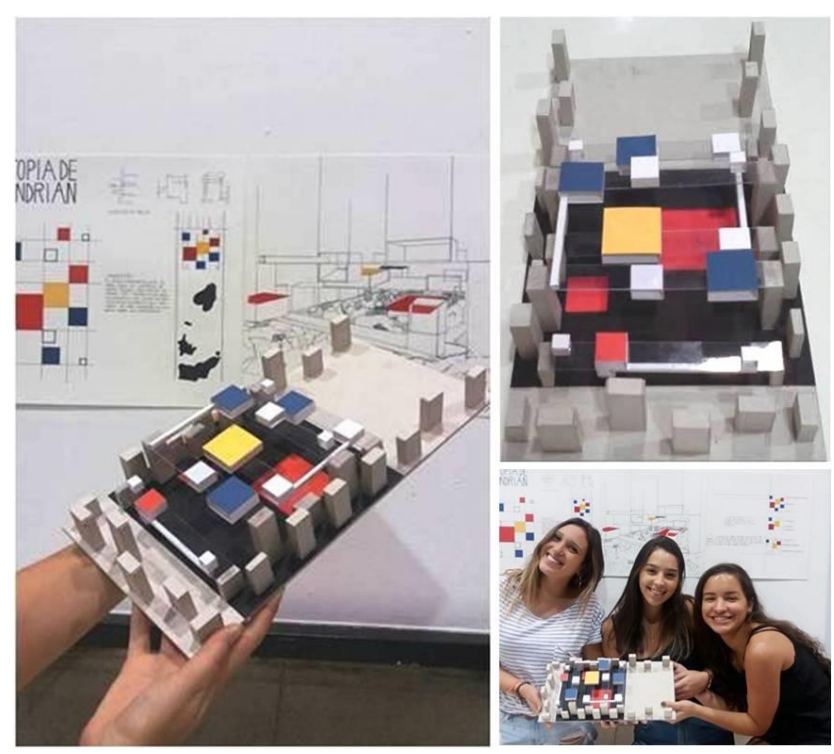

Fonte: Acervo dos autores.

\section{CONSIDERAÇÕES FINAIS}

Muitos estudantes de arquitetura acreditam que é mais importante detalhar o projeto, ao invés de "perder tempo" com os sonhos e as divagações anteriores ao lançamento de diferentes hipóteses de partido. Com isso, menosprezam os momentos de ócio criativo.

Sonhar e tentar tornar os sonhos realidade pode incentivar o desabrochar de mentes criadoras. Ter coragem para pensar alto e lançar um partido arrojado, ou uma proposta fictícia para um mundo utópico, não constituem, a nosso ver, atitudes irresponsáveis, e sim exercícios próprios de um ser irrequieto e criativo. Afinal somente os planos e projetos construídos devem ser considerados como grandes obras? A resposta parece estar contemplada na afirmação de Gramsci: a obra de arte é o projeto [...] Um arquiteto pode ser julgado um grande artista por seus planos, ainda que não os tenha edificado materialmente (apud PULS, 2006, p. 127).

Propor diferentes respostas para um mesmo problema, ou antecipar cenários e inventar soluções possíveis ou impossíveis, faz parte do processo de especulação a ser estimulado no universo universitário. É o lançamento de ideias, por meio de muitas tentativas e erros, que faz com que os alunos, acumulando experiências, se qualifiquem para projetar e construir para uma sociedade melhor.

Apesar de gratificante, criar é um processo que exige concentração, disciplina e organização, assim como ensinar pressupõe rigor tanto na elaboração do plano pedagógico quanto no acompanhamento sistemático 
de seu desenvolvimento. Como observa Paulo Freire, [...] jamais compreendi a prática educativa como uma experiência a que faltasse o rigor em que se gera a necessária disciplina intelectual (1977, p. 92).

\section{REFERÊNCIAS}

ARÍS, Carlos Martí. Abstracción em arquitectura: uma definición. Barcelona: Universitat Politecnica da Catalunya/DPA, 2000. <https://issuu.com/maearq_med/docs/dpa16_abstraccion>. Acesso em 22.032015. $47 . \quad$ <https://www.ufrgs.br/propar/publicacoes/ARQtextos/PDFs_revista_3. El arte y la ciencia: dos modos de hablar con el mundo. Porto Alegre: UFRGS/Propar, 2003, pp. 414/04Carlos\%20Mart\%C3\%AD\%20Ar\%C3\%ADs.pdf>. Acesso em 22.03.2015.

BAUMAN, Zygmunt. Modernidade líquida. Rio de Janeiro: Zahar, 2001.

. Estranhos à nossa porta. Rio de Janeiro: Zahar, 2017.

BOSI, A. Dialética da colonização. São Paulo: Companhia das Letras, 2002.

DE MASI, Domenico. O ócio criativo. Rio de Janeiro: Sextante, 2000.

FELLINI, Federico. Eu sou um grande mentiroso. Entrevista a DamienPettigrew. Rio de Janeiro: Nova Fronteira, 1995.

FREIRE, Paulo. Pedagogia da autonomia. Saberes necessários a prática educativa. 4ed. São Paulo. Paz e Terra, 1997.

HUIZINGA, Johan. Homo ludens. São Paulo: Perspectiva, 2000.

JUNG, Carl Gustav. O eu e o inconsciente. Petrópolis: Vozes, 2008.

MARCUSE, Herbert. Art and revolution. In: MARCUSE, H. Counter-revolution and revolte. Boston: Beacon Press, 1972 , pp.79-128.

A dimensão estética. Trad. Maria Elisabete Costa. Lisboa: Edições 70, 1986.

NUNES, Tiago Ribeiro. Arte e transformação. Goiânia: UFG-CAC/ Espaço em Revista, 2009 vol. 11 n 1 jan/jun. p. 141 150. <https://www.revistas.ufg.br/espaco/article/download/13675/9092>.Acesso em 20.07.2015.

PALLASMAA, Juhani. Os olhos da pele: a arquitetura e os sentidos. Porto Alegre: Bookman, 2011.

PUIG, Armand. La Sagrada Familia según Gaudí. Barcelona: El Aleph Editores, 2011.

PULS, Maurício. Arquitetura e filosofia. São Paulo: Annablume, 2006.

WORRINGER, Wilhelm. Abstraction and Empathy. Tradução de Michael Bullock. New York: International University Press, 1953.

\section{NOTAS}

${ }^{1}$ Disponível em: https://theartstack.com/artist/theo-van-doesburg/the-cow-4-stages-of-abstraction-1917

${ }^{2}$ Disponíveis em: https://commons.wikimedia.org/wiki/File:Cripta G\%C3\%BCell20.jpg ;

https://commons.wikimedia.org/wiki/File:Gaudi teresianas 001.jpg e http://descobrintben.blogspot.com.br/2012/09/la-pedrerasecreta.html

${ }^{3}$ Disponíveis em: https://en.wikipedia.org/wiki/City of Arts and Sciences\#/media/File:Hemisf\%C3\%A8ric 05102005.jpg e https://commons.wikimedia.org/wiki/File:Gare do Oriente (10000658884).jpg

NOTA DO EDITOR (*) O conteúdo do artigo e as imagens nele publicadas são de responsabilidade do(s) autor(es). 